\title{
Unexpected course of a Williamson ether synthesis
}

\author{
Klaus-Peter Zeller, ${ }^{a *}$ Peter Haiss, ${ }^{a}$ Meike Hartmann, ${ }^{a}$ and Klaus Eichele ${ }^{b}$ \\ ${ }^{a}$ Institut für Organische Chemie, ${ }^{b}$ Institut für Anorganische Chemie \\ Universität Tübingen, D-72076 Tübingen \\ E-mail:kpz@uni-tuebingen.de
}

\section{Dedicated to Professor Atta-ur-Rahman on the occasion of his $65^{\text {th }}$ birthday}

\begin{abstract}
The Williamson ether synthesis between the sodium salt of methyl mandelate and methyl $\alpha$ bromophenylacetate was reinvestigated. In addition to the expected ether product cis-dimethyl 2,3-diphenyloxirane-2,3-dicarboxylate, methyl phenylacetate and methyl phenylglyoxylate were obtained. Their formation is explained by an initial $\alpha$-elimination producing an $\alpha$-oxo-carbene from the $\alpha$-bromoester. This is followed by a hydride transfer from the sodium salt of methyl mandelate to the carbenic intermediate furnishing the enolate of methyl phenylacetate as reduction product and methyl phenylglyoxylate as oxidation product. Finally, the methyl phenylglyoxylate reacts with the enolate of the $\alpha$-bromoester in a diastereospecific Darzens condensation to the cis-oxirane (cis-conformation confirmed by single crystal structure analysis). In this series of parallel and sequential reactions, the sodium salt of methyl mandelate displays 3 modes of action: nucleophile (ether synthesis), base ( $\alpha$-elimination) and hydride donor (redox process).
\end{abstract}

Keywords: $\alpha$-Elimination, hydride transfer, Darzens glycidic ester condensation

\section{Introduction}

3,5-Diphenyl-2,6-dioxo-1,4-dioxane (1) has been suspected as intermediate in the thermolysis of mandelic acid (2). To the best of our knowledge the literature gives only one reference for the synthesis of compound 1 published in the year 1933. ${ }^{1}$ This synthesis comprises of 3 apparently simple steps: formation of the ether $\mathbf{5}$ by a Williamson synthesis (scheme 1), followed by saponification to the corresponding dicarboxylic acid and finally dehydration with formation of the cyclic anhydride 1, which should be obtained as a diastereomeric mixture of the meso-and racemic trans-product. In ref. 1 the stereochemistry of the product obtained was not investigated. 
<smiles>O=C1OC(=O)C(c2ccccc2)OC1c1ccccc1</smiles>

1<smiles>O=C(O)C(O)c1ccccc1</smiles>

2

When repeating the procedure for the synthesis of the ether 5 as described by Hurd and Raterink $^{1}$ a complex product mixture was obtained. In this communication the full range of competing and sequential reaction pathways is analyzed and discussed.<smiles>COC(=O)[C@H]([O+])[C@@H]([O+])c1ccccc1</smiles>

$[3-\mathrm{H}]^{-}$
4<smiles>COC(=O)C(OC(c1ccccc1)[PH](=O)(O)c1ccccc1)C(=O)OC</smiles><smiles>COC(=O)[C@@H](O[C@@H](C(=O)OC)c1ccccc1)c1ccccc1</smiles>

rac. 5

Scheme 1. Williamson ether synthesis of the diastereomeric bis(methoxycarbonylphenylmethyl)ethers 5. In ref. 1 the corresponding ethyl esters were used. To simplify ${ }^{1} \mathrm{H}-\mathrm{NMR}$ analysis of the product mixture we applied the methyl esters.

\section{Results}

When attempting the synthesis of the ether 5 by reaction of the sodium salt of racemic methyl mandelate with racemic methyl $\alpha$-bromophenylacetate according to scheme 1 , methyl phenylacetate (6), methyl phenylglyoxylate (7), cis-dimethyl 2,3-diphenyloxirane-2,3dicarboxylate (8), and meso- and racemic dimethyl 1,2-diphenylsuccinate (9) could be identified as additional reaction products. In table 1 the composition of the reaction mixture is compiled.<smiles>COC(=O)Cc1ccccc1</smiles>

6<smiles>COC(=O)C(=O)c1ccccc1</smiles>

7

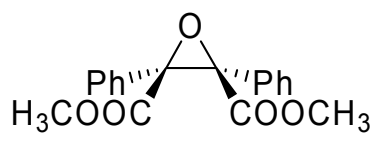

8<smiles>COC(=O)[C@H](c1ccccc1)[C@H](C(=O)OC)c1ccccc1</smiles>

9 
Table 1. Composition of the mixture obtained by reaction of the sodium alcoholate of methyl mandelate and methyl $\alpha$-bromophenylacetate after work-up with aqueous $\mathrm{NH}_{4} \mathrm{Cl}$

\begin{tabular}{llllllll}
\hline compound & $\mathbf{3}$ & $\mathbf{4}$ & $\mathbf{5}$ & $\mathbf{6}$ & $\mathbf{7}$ & $\mathbf{8}$ & $\mathbf{9}$ \\
\hline$\%^{\mathrm{a}}$ & 35.3 & 16.2 & $16.6^{\mathrm{b}}$ & 16.0 & 4.4 & 10.7 & $0.8^{\mathrm{c}}$ \\
\hline
\end{tabular}

${ }^{\mathrm{a}}$ Determined by ${ }^{1} \mathrm{H}-\mathrm{NMR}$ integration of the ester methoxy protons except for compound $\mathbf{6}$, where the better separated protons of the methylene group were used. The yields given are mean values of 5 experiments (standard deviation \pm 0.2 ). The NMR data are given in the experimental part.

${ }^{\mathrm{b}} \sim 1.14: 1$ mixture of two diastereomers.

${ }^{c} 1: 1$ mixture of the meso and racemic diastereomers.

The oxirane 8 could be precipitated in pure form from a solution of the reaction products in methanol at $-23^{\circ} \mathrm{C}$ as a polycrystallinic material (m.p. $127-129^{\circ} \mathrm{C}$ ). Recrystallization from dichloromethane/pentane furnishes a polymorphic modification of m.p. $131-132^{\circ} \mathrm{C}$. Both polymorphic modifications show identical ${ }^{1} \mathrm{H}-,{ }^{13} \mathrm{C}-\mathrm{NMR}$-, and mass spectra. The meso configuration is confirmed by the transformation of $\mathbf{8}$ to the bicyclic anhydride $\mathbf{1 1}$ via the route outlined in scheme 2 and by a X-ray structure analysis (see below).

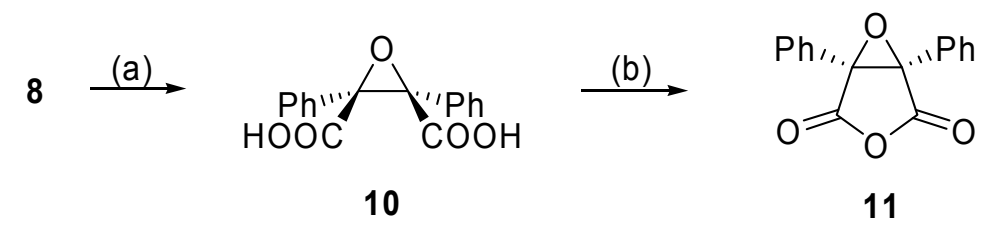

(a) $\mathrm{NaOCH}_{3} / \mathrm{H}_{2} \mathrm{O}, 20^{\circ} \mathrm{C}$, (b) $\mathrm{CH}_{3} \mathrm{COCl}$, reflux.

Scheme 2. Transformation of the diester $\mathbf{8}$ to the bicyclic anhydride $\mathbf{1 1 .}$

The residues from several runs, depleted of the oxirane $\mathbf{8}$ as much as possible by crystallization, were combined and subjected to distillation up to $100^{\circ} \mathrm{C}$ at $0.1 \mathrm{mbar}$. By this operation large amounts of volatile components (starting compounds and esters 6 and 7) could be removed and the diastereomeric ethers 5 were enriched in the remaining oil to over $44 \%$. By subsequent column chromatography on silica gel with petroleum ether $\left(40^{\circ} \mathrm{C} / 60^{\circ} \mathrm{C}\right)$ and dichloromethane as eluent the diastereomeric mixture of $\mathbf{5}$ and small amounts of the diesters $\mathbf{9}$ could be isolated together with additional amounts of the oxirane $\mathbf{8}$ and the starting materials $\mathbf{3}$ and 4 , which were incompletely removed by crystallization and distillation. Substantial total losses were noticed in the chromatographic separation.

After completion of the structural elucidation of $\mathbf{8}$ a literature search revealed that compounds 8,10 and $\mathbf{1 1}$ have been synthesized before by a completely different route. ${ }^{2}$ 


\section{Discussion}

The oxirane 8, which has been formed in similar amounts as the ether $\mathbf{5}$, can be considered as a formal dehydrogenation product of the latter. This points to a redox process as parallel reaction to the Williamson ether synthesis (scheme 1) with the oxirane $\mathbf{8}$ as oxidation and methyl phenylacetate (6), also present in relatively large quantities in the reaction mixture, as reduction product.

The $\alpha$-bromoester 4 is a $\mathrm{CH}$-acidic compound and may therefore partly react with the alcoholate of methyl mandelate $[3-\mathrm{H}]^{-}$under proton abstraction. Subsequent loss of bromide from the bromoenolate 12 intermediately formed in the deprotonation step constitutes an $\alpha$ elimination process generating the $\alpha$-oxocarbene $\mathbf{1 3}$ as reactive intermediate. Finally, interaction of the potential hydride donor $[3-\mathrm{H}]^{-}$with the electron deficient carbene $\mathbf{1 3}$ results in a redox process yielding the enolate of methyl phenylacetate $[6-\mathrm{H}]^{-}$as reduction and methyl phenylglyoxylate 7 as oxidation products. The complete sequence of $\alpha$-elimination and redox reaction is summarized in scheme 3 .

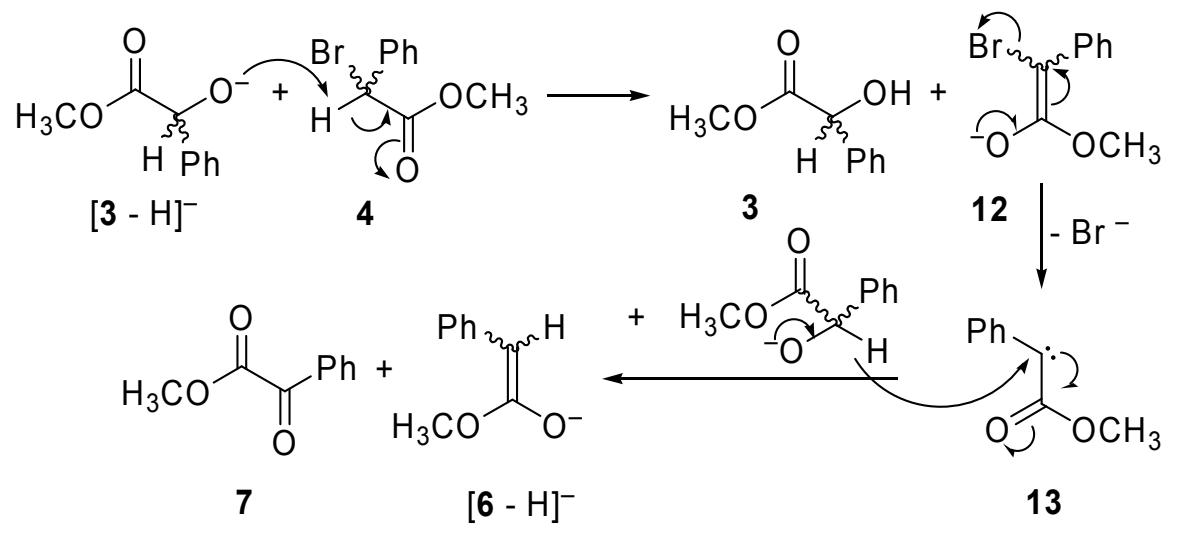

Scheme 3. The $\alpha$-elimination - redox sequence leading to the enolate $[6-\mathrm{H}]^{-}$and methyl phenylglyoxylate (7).

The $\alpha$-oxoester 7 does not survive under the reaction conditions. It reacts immediately with the bromoenolate 12, undergoing a Darzens glycidic ester condensation. Both the threo (14) and the erythro (15) addition products are undoubtedly formed in the first step. However, only the thermodynamically less favorable cis-oxirane $\mathbf{8}$ is obtained as reaction product. The remarkable diastereospecificity of the Darzens reaction is well known ${ }^{3,4}$ and can be rationalized in terms of an equilibrium between the two aldol addition products and kinetic control in the cyclization step by a favorable orbital overlap in the transition state of the oxirane formation from the threo diastereomer. $^{4}$ 


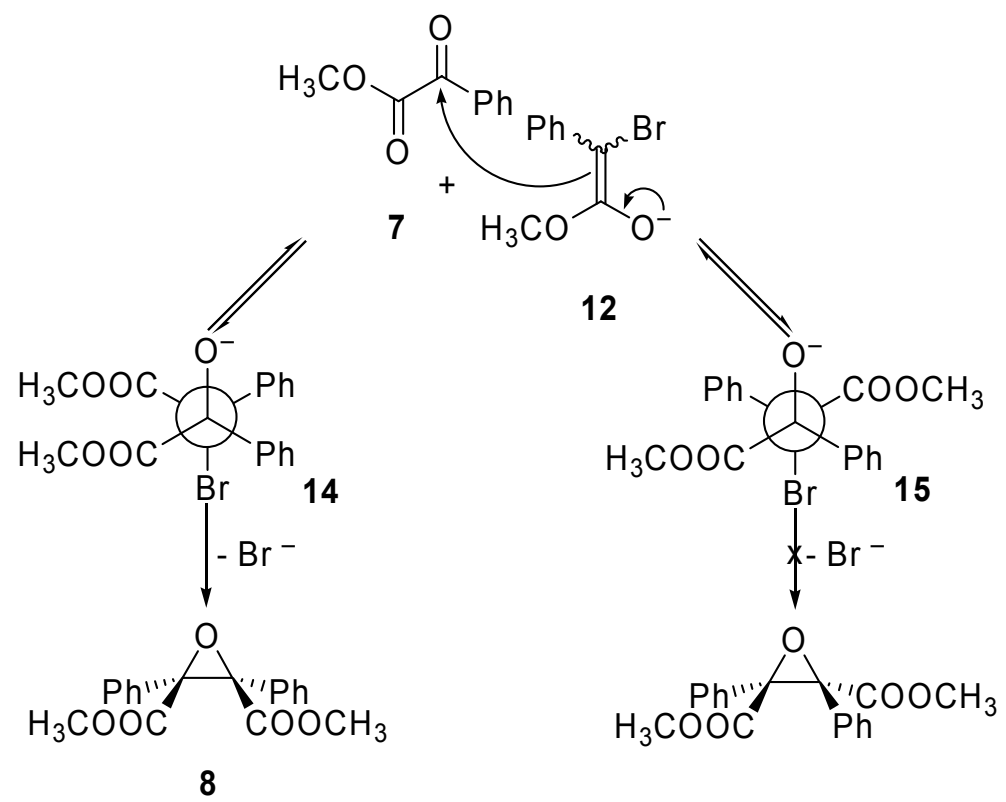

Scheme 4. Darzens glycidic ester condensation of the intermediate $\alpha$-oxoester 7 and the bromoenolate $\mathbf{1 2}$.

In order to test the suggested pathway leading to compound $\mathbf{8}$ a mixture of the $\alpha$-oxoester 7 and the $\alpha$-bromoester 4 were reacted in the presence of an equimolar amount of base. Indeed, in a smooth stereospecific reaction the cis-oxirane $\mathbf{8}$ was obtained.

It is worthwhile to consider the overall stoichiometry for the formation of the surprising product 8 from the starting compounds $[3-\mathrm{H}]^{-}$and 4 . This can be obtained by combining the reaction sequences of schemes 3 and 4 and results in the overall reaction given in scheme 5 .

3<smiles>COC(=O)[C@H]([O-])c1ccccc1</smiles>

$[3-\mathrm{H}]^{-}$<smiles>COC(=O)[C@H](O)c1ccccc1</smiles>

3

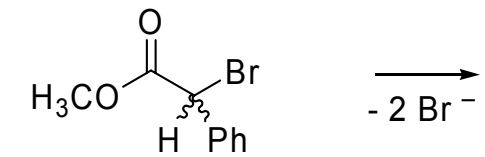

4

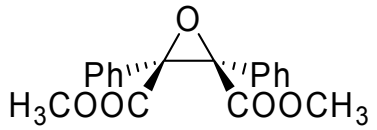

8

Scheme 5. Overall stoichiometry for the formation of the cis-oxirane $\mathbf{8}$.

From this equation it follows that on the product side two equivalents of methyl mandelate (3) are concomitantly formed together with the cis-oxirane 8. In contrast to its deprotonation 
product $[3-\mathrm{H}]^{-}$methyl mandelate cannot react further, neither as nucleophile (scheme 1) nor as base and hydride donor (scheme 3 ). Therefore, it appears as final reaction product and explains the more than $60 \%$ of the recovered methyl mandelate in the reaction mixture. Furthermore, the overall stoichiometry (scheme 5) requires that the cis-oxirane $\mathbf{8}$ and methyl phenylacetate (6) should be present in a ratio of 1:1 after aqueous work-up. The experimental ratio is $\sim 0.7: 1$ (table 1). This deviation is readily explained with the amount of methyl phenylglyoxylate (7) which survived in the reaction mixture. The sum of $\mathbf{7}$ and $\mathbf{8}$ (oxidation products) is within experimental error equal to the amount of $\mathbf{6}$ (reduction product).

In addition to the reaction products described so far trace amounts of the two diastereomers of dimethyl diphenylsuccinate (9) could be isolated and identified by comparison of their spectral data with literature values. Their formation may be rationalized by nucleophilic displacement of bromine in $\mathbf{4}$ by the enolate of methyl phenylacetate.

X-ray structural analysis of cis-dimethyl 2,3-diphenyloxirane-2,3-dicarboxylate (8) and cis1,5-diphenyl-3,6-dioxabicyclo[3.1.0]hexane-2,4-dione (11)

As discussed in the previous sections, methyl phenylglyoxylate and the enolate of methyl $\alpha$ bromophenylacetate combine in a stereospecific fashion to cis-dimethyl 2,3-diphenyloxirane-2,3dicarboxylate. The stereochemical course of this $\mathrm{C}, \mathrm{C}$-bond formation according to the Darzens glycidic ester condensation follows from its transformation to the anhydride $\mathbf{1 1}$ and could be confirmed further by X-ray structure analysis. In the following the structural data are reported.

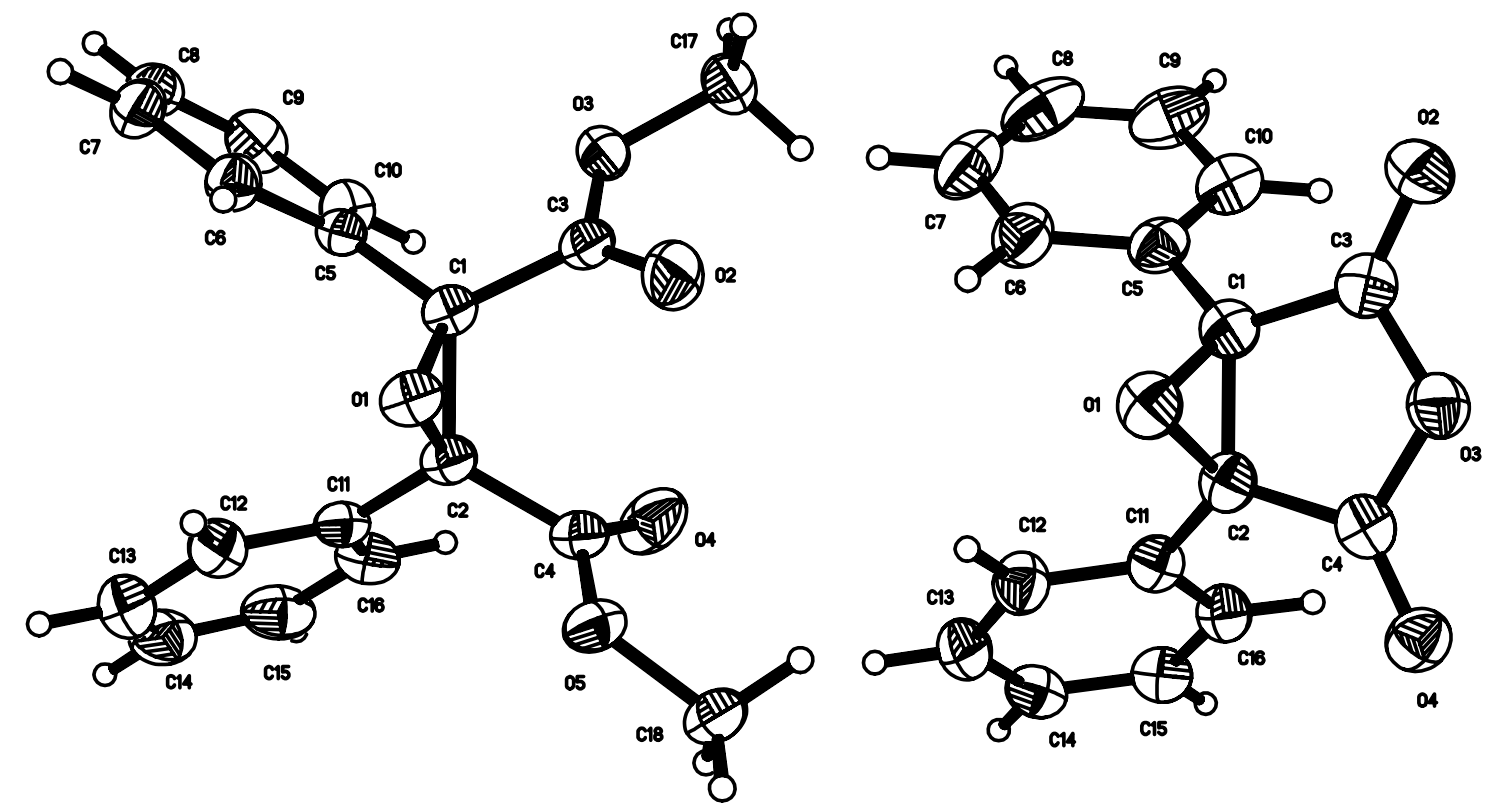

Figure 1. ORTEP plot of the molecular structure of cis-dimethyl 2,3-diphenyloxirane-2,3dicarboxylate 8 (left) and the resulting cis-1,5-diphenyl-3,6-dioxabicyclo[3.10]hexane-2,4-dione 11 (right) in the crystal, drawn at the 50\% probability level. 
Table 2. Selected bond lengths $[\AA]$ and angles [deg] for the cis-oxirane $\mathbf{8}$ and the corresponding anhydride 11

\begin{tabular}{lll}
\hline & Epoxide 8 & Anhydride 11 \\
\hline $\mathrm{O}(1)-\mathrm{C}(1)$ & $1.440(2)$ & $1.444(2)$ \\
$\mathrm{O}(1)-\mathrm{C}(2)$ & $1.425(1)$ & $1.443(2)$ \\
$\mathrm{C}(1)-\mathrm{C}(2)$ & $1.497(2)$ & $1.500(2)$ \\
$\mathrm{O}(2)-\mathrm{C}(3)$ & $1.195(2)$ & $1.193(2)$ \\
$\mathrm{O}(3)-\mathrm{C}(3)$ & $1.329(2)$ & $1.392(2)$ \\
$\mathrm{O}(3)-\mathrm{C}(4)$ & - & $1.399(2)$ \\
$\mathrm{O}(4)-\mathrm{C}(4)$ & $1.199(2)$ & $1.184(2)$ \\
$\mathrm{O}(5)-\mathrm{C}(4)$ & $1.320(2)$ & - \\
$\mathrm{C}(1)-\mathrm{C}(3)$ & $1.518(2)$ & $1.501(2)$ \\
$\mathrm{C}(2)-\mathrm{C}(4)$ & $1.510(2)$ & $1.511(2)$ \\
& & \\
$\mathrm{C}(2)-\mathrm{O}(1)-\mathrm{C}(1)$ & $62.99(8)$ & $62.63(10)$ \\
$\mathrm{O}(1)-\mathrm{C}(1)-\mathrm{C}(2)$ & $58.02(7)$ & $58.65(10)$ \\
$\mathrm{O}(1)-\mathrm{C}(2)-\mathrm{C}(1)$ & $58.98(7)$ & $58.72(10)$ \\
\hline
\end{tabular}

Unequivocal confirmation for the cis arrangement of phenyl groups comes from the crystal structures of $\mathbf{8}$ and $\mathbf{1 1}$ (Fig. 1). The epoxide rings in $\mathbf{8}$ and $\mathbf{1 1}$ are typical when compared with the other 1863 epoxides that are available in the Cambridge Structural Database version 5.27 (November 2005): the bond angle at oxygen is slightly greater than $60^{\circ}$, while the angles at both carbon atoms are more acute (Tab. 2). Formation of the five-membered anhydride ring causes the angle between the phenyl groups to widen: in 8 the angle between $\mathrm{C}(1)-\mathrm{C}(5)$ and $\mathrm{C}(2)-\mathrm{C}(11)$ is $60.7^{\circ}$ but increases to $72.1^{\circ}$ in 11 . The interplanar angle between the benzene rings and the oxirane moiety are affected to a lesser extent when going from 8 to 11 . They change from $57.48^{\circ}$ $(\mathrm{C}(5)-\mathrm{C}(10))$ and $63.79^{\circ}(\mathrm{C}(11)-\mathrm{C}(16))$ in 8 to $64.48^{\circ}$ and $62.52^{\circ}$ in $\mathbf{1 1}$.

\section{Experimental Section}

General Procedures. ${ }^{1} \mathrm{H}$ NMR and ${ }^{13} \mathrm{C}$-NMR spectra were recorded on a Bruker Avance 400 spectrometer. Mass spectra were obtained on a TSQ-70 Quadrupole mass spectrometer (EI, 70 $\mathrm{eV})$.

Commercial samples of high purity of methyl $\alpha$-bromophenylacetate (4), methyl phenylacetate (6) and methyl phenylglyoxylate (7) were used as starting and reference compounds, resp. These compounds show the following ${ }^{1} \mathrm{H}-\mathrm{NMR}$ data.

4: ${ }^{1} \mathrm{H}-\mathrm{NMR}\left(400 \mathrm{MHz}, \mathrm{CDCl}_{3}\right) \delta 3.79(3 \mathrm{H}, \mathrm{s}), 5.37(1 \mathrm{H}, \mathrm{s}), 7.32-7.40(3 \mathrm{H}, \mathrm{m}), 7.52-7.58(2 \mathrm{H}$, $\mathrm{m})$.

6: ${ }^{1} \mathrm{H}-\mathrm{NMR}\left(400 \mathrm{MHz}, \mathrm{CDCl}_{3}\right) \delta 3.63(2 \mathrm{H}, \mathrm{s}), 3.69(3 \mathrm{H}, \mathrm{s}), 7.24-7.36(5 \mathrm{H}, \mathrm{m})$. 
7: ${ }^{1} \mathrm{H}-\mathrm{NMR}\left(400 \mathrm{MHz}, \mathrm{CDCl}_{3}\right) \delta 3.97(3 \mathrm{H}, \mathrm{s}), 7.47-7.54(2 \mathrm{H}, \mathrm{m}), 7.62-7.69(1 \mathrm{H}, \mathrm{m}), 7.98-8.04$ $(2 \mathrm{H}, \mathrm{m})$.

Methyl mandelate (3). Compound 3 was prepared from mandelic acid (2) by reaction with excess ethereal diazomethane according to the standard procedure and purified by recrystallization from methanol.

${ }^{1} \mathrm{H}-\mathrm{NMR}\left(400 \mathrm{MHz} \mathrm{CDCl}_{3}\right) \delta 3.75(3 \mathrm{H}, \mathrm{s}), 5.18(1 \mathrm{H}, \mathrm{s}), 7.31-7.48(5 \mathrm{H}, \mathrm{m})$.

\section{Reaction of the sodium salt $\mathrm{Na}[3-\mathrm{H}]$ with the $\alpha$-bromoester 4}

Methyl mandelate $(3,3.45 \mathrm{~g}, 20.8 \mathrm{mmol})$ was allowed to react with finely dispersed sodium metal $(0.45 \mathrm{~g}, 19.6 \mathrm{mmol})$ in ether $(55 \mathrm{ml})$. After $5 \mathrm{~h}$ the hydrogen evolution ceased and methyl a-bromophenylacetate $(4,4.43 \mathrm{~g}, 19.3 \mathrm{mmol})$ dissolved in ether $(10 \mathrm{ml})$ was added in one portion. To enhance the solubility of the alcoholate in the solvent ether and to catalyze the displacement of bromine in 4 tetrabutylammonium iodide $(80 \mathrm{mg}, 0.2 \mathrm{mmol}$ ) was added and the mixture stirred at $20^{\circ} \mathrm{C}$ for $24 \mathrm{~h}$. After addition of excess aqueous $\mathrm{NH}_{4} \mathrm{Cl}$ and separation of the organic phase the aqueous phase was extracted with ether $(5 \times 30 \mathrm{ml})$. The combined organic phase was washed with brine $(2 \times 50 \mathrm{ml})$, dried over $\mathrm{Na}_{2} \mathrm{SO}_{4}$ and the solvent removed on a rotary evaporator. The remaining oil (6.5 g) was analyzed by ${ }^{1} \mathrm{H}-\mathrm{NMR}$ spectroscopy. The result is given in table 1.

The crude reaction product was dissolved in the minimum amount of methanol to obtain a clear solution and allowed to stand at $-23^{\circ} \mathrm{C}$ for $20 \mathrm{~h}$. The oxirane $8(0.76 \mathrm{~g}, 23 \%)$ precipitated as a polycrystallinic modification, m.p. $127-129^{\circ} \mathrm{C}$. Repeated recrystallization from pentane/dichloromethane furnished a polymorphic modification, m.p. $131-132^{\circ} \mathrm{C}$, suitable for Xray structural analysis. The spectral data are identical with a reference compound prepared from 7 and methyl $\alpha$-bromophenylacetate (4) by Darzens condensation. As shown by ${ }^{1} \mathrm{H}-\mathrm{NMR}$ integration $\sim 35 \%$ of the oxirane 8 remained in the mother liquor. After depletion in compound 8 the combined crude products of several runs $(10.3 \mathrm{~g})$ were subjected to distillation up to $100^{\circ} \mathrm{C}$ at 0.1 mbar to remove volatile components. In the residue obtained the diastereomeric ethers $\mathbf{5}$ were enriched to $44 \%$ as shown by ${ }^{1} \mathrm{H}-\mathrm{NMR}$ integration.

A sample of $3.5 \mathrm{~g}$ was chromatographed on $100 \mathrm{~g}$ silica gel (70-230 mesh) in a water cooled column (eluent: petroleum ether $\left(40^{\circ} \mathrm{C} / 60^{\circ} \mathrm{C}\right) /$ dichloromethane $\left.4: 1 \rightarrow 2: 3\right)$. The following fractions were eluted:

Starting compound 4 (0.5 g); diastereomeric mixture of 9 (40 mg); diastereomeric mixture of 5 together with product $\mathbf{8}(1.1 \mathrm{~g})$, ratio 5/8 1: 0.8; starting compound $\mathbf{3}(0.2 \mathrm{~g})$.

A further column chromatography on silica gel with petroleum ether/dichloromethane 1:9 furnished a pure sample of the diastereomers of 5 .

Dimethyl diphenylsuccinate (9) (diastereomeric mixture).

meso-9. ${ }^{1} \mathrm{H}-\mathrm{NMR}\left(400 \mathrm{MHz}, \mathrm{CDCl}_{3}\right) \delta 3.40(6 \mathrm{H}, \mathrm{s}), 4.39(2 \mathrm{H}, \mathrm{s}), 7.27-7.52(10 \mathrm{H}, \mathrm{m})$.

rac. 9. ${ }^{1} \mathrm{H}-\mathrm{NMR}\left(400 \mathrm{MHz}, \mathrm{CDCl}_{3}\right) \delta 3.70(6 \mathrm{H}, \mathrm{s}), 4.26(2 \mathrm{H}, \mathrm{s}), 6.95-7.18(10 \mathrm{H}, \mathrm{m})$.

The data are in agreement with those found in ref. 5. Integration of the singlet at 4.39 (meso) and $4.26(d, l)$ indicate a $1: 1$ mixture. 
Crystallization from dichloromethane furnished meso-9 as a pure sample m.p. $233-235^{\circ} \mathrm{C}$ (ref. 5: m.p. $\left.235-238^{\circ} \mathrm{C}\right)$.

Bis(methoxycarbonylphenylmethyl)ether (5) (diastereomeric mixture). ${ }^{1} \mathrm{H}-\mathrm{NMR}(400 \mathrm{MHz}$, $\left.\mathrm{CDCl}_{3}\right) \delta 3.69,3.72(6 \mathrm{H}, 2 \mathrm{~s}), 5.00,5.02(2 \mathrm{H}, 2 \mathrm{~s}), 7.32-7.40(6 \mathrm{H}, \mathrm{m}), 7.41-7.49(4 \mathrm{H}, \mathrm{m}) ;{ }^{13} \mathrm{C}-$ NMR $\left(100 \mathrm{MHz}, \mathrm{CDCl}_{3}\right) \delta 52.3,78.6,78.8,127.4,127.6,128.7,135.3,135.4,170.4,170.5$; EIMS (70 eV), m/z (\%) $255\left(\left[\mathrm{M}-\mathrm{CO}_{2} \mathrm{CH}_{3}\right]^{+}, 26\right), 150(34), 149(100), 121$ (45).

The ratio of the singlets at 3.69/3.72 and 5.00/5.02 indicates a 1.14:1 diastereomeric mixture. cis-Dimethyl 2,3-diphenyloxirane-2,3-dicarboxylate (8) by Darzens condensation. To a solution of potassium tert.-butylate $(10 \mathrm{ml}, 1$-molar $)$ in THF a mixture of methyl $\alpha$ bromophenylacetate $(2.2 \mathrm{~g}, 10 \mathrm{mmol})$ and methyl phenylglyoxylate $(1.65 \mathrm{~g}, 10 \mathrm{mmol})$ in THF (1 $\mathrm{ml}$ ) was added dropwise at $-10^{\circ} \mathrm{C}$. The mixture was allowed to stand overnight at $20^{\circ} \mathrm{C}$. The mixture was brought to $\mathrm{pH} 4$ by addition of acetic acid and poured into ice water $(30 \mathrm{ml})$. After extraction with ether $(4 \times 40 \mathrm{ml})$ the organic phase was washed with brine $(2 \times 50 \mathrm{ml})$, dried over $\mathrm{Na}_{2} \mathrm{SO}_{4}$ and the solvent removed on a rotary evaporator. The crude product $(3.1 \mathrm{~g})$ was purified by recrystallization from methanol followed by recrystallization from pentane/dichloromethane, yield: $2.0 \mathrm{~g}(64 \%)$, m.p. $131-132^{\circ} \mathrm{C}$.

${ }^{1} \mathrm{H}-\mathrm{NMR}\left(400 \mathrm{MHz}, \mathrm{CDCl}_{3}\right) \delta 3.82(6 \mathrm{H}, \mathrm{s}), 7.11-7.17(6 \mathrm{H}, \mathrm{m}), 7.30-7.36(4 \mathrm{H}, \mathrm{m}) ;{ }^{13} \mathrm{C}-\mathrm{NMR}$ $\left(100 \mathrm{MHz}, \mathrm{CDCl}_{3}\right) 53.2$, 68.9, 127.5, 127.8, 128.6, 130.7, 167.5; EI-MS (70 eV), m/z: (\%) 312 $\left(\mathrm{M}^{+*}, 4\right), 266$ (36), 253 (10), 238 (16), 221 (27), 193 (10), 179 (98), 165 (21), 151 (27), 149 (19), 121 (37), 105 (100), 77 (43).

cis-2,3-Diphenyloxirane-2,3-dicarboxylic acid (10). The diester 8 was saponificated to the dibasic acid 10 as described in ref. 2, yield: 79\%, m.p. $121-123{ }^{\circ} \mathrm{C} .{ }^{1} \mathrm{H}-\mathrm{NMR}\left(400 \mathrm{MHz}, \mathrm{CDCl}_{3}\right)$ $\delta$ 7.13-7.21 (6H, m), 7.31-7.41 (4H, m); ${ }^{13} \mathrm{C}-\mathrm{NMR}\left(100 \mathrm{MHz}, \mathrm{CDCl}_{3}\right) \delta 69.7,128.3,128.5$, 129.1, 132.8, 168.3; EI-MS (70 eV), $m / z 266\left(\left[\mathrm{M}-\mathrm{H}_{2} \mathrm{O}\right]^{+\cdot}\right)$.

cis-1,5-Diphenyl-3,6-dioxabicyclo[3.10]hexane-2,4-dione (11). Dehydration of 10 to the anhydride 11 is performed according to ref. 2, yield 42\%, m.p. $141-142{ }^{\circ} \mathrm{C}$. ${ }^{1} \mathrm{H}-\mathrm{NMR}(400 \mathrm{MHz}$, acetone- $\left.\mathrm{d}_{6}\right)$ 7.34-7.42 (6H, m), 7.53-7.59 (4H, m); ${ }^{13} \mathrm{C}-\mathrm{NMR}\left(100 \mathrm{MHz}\right.$, acetone- $\left.\mathrm{d}_{6}\right)$ 69.3, 125.4, 129.1, 129.2, 131.0, 165.7; EI-MS (70 eV), $m / z 266\left(\mathrm{M}^{+\cdot}\right)$.

\section{Crystal structure analysis of compounds 8 and 11}

Crystals suitable for a single crystal X-ray diffraction investigation were grown from solutions in dichloromethane/pentane. Data were collected at a temperature of 173(2) K on a Stoe IPDS 2T diffractometer using Mo-K $\alpha$ irradiation $(\lambda=0.71073 \AA)$ and were corrected for Lorentz and polarization effects.

Crystal structure analysis of $\mathbf{8}: \mathrm{C}_{18} \mathrm{H}_{16} \mathrm{O}_{5}, \mathrm{M}=312.31$. Crystal size $0.50 \times 0.30 \times 0.08 \mathrm{~mm}$. Monoclinic, space group $C 2 / \mathrm{c}, a=16.024(4), b=7.0035(14), c=28.674(7) \AA, \beta=102.41(4)^{\circ}, \mathrm{Z}$ $=8$. Theta range for data collection: 3.19 to $29.41^{\circ}, 25521$ reflections collected, 4258 independent reflections $[\mathrm{R}(\mathrm{int})=0.0484]$, direct methods, full-matrix least-squares refinement on $F^{2}, 211$ parameters, GooF $=1.046, \mathrm{R} 1[\mathrm{I}>2 \sigma(\mathrm{I})]=0.0432$, wR2 (all data) $=0.1081$, largest diff. peak and hole: 0.266 and $-0.227 \mathrm{e} \AA^{-3}$. 
Crystal structure analysis of 11: $\mathrm{C}_{16} \mathrm{H}_{10} \mathrm{O}_{4}, \mathrm{M}=266.24$. Crystal size $0.40 \times 0.20 \times 0.20 \mathrm{~mm}$. Orthorhombic, space group $P 2{ }_{1}{ }_{1}{ }_{1} 1, a=5.5581(5), b=9.6828(11), c=23.340(3) \AA, Z=4$. Theta range for data collection: 3.36 to $26.91^{\circ}, 14951$ reflections collected, 2662 independent reflections $[\mathrm{R}(\mathrm{int})=0.0685]$, direct methods, full-matrix least-squares refinement on $F^{2}, 182$ parameters, GooF $=1.089, \mathrm{R} 1[\mathrm{I}>2 \sigma(\mathrm{I})]=0.0421$, wR2 (all data) $=0.0842$, largest diff. peak and hole: 0.138 and -0.159 e $\AA^{-3}$.

CCDC 626068 (8) and 626069 (11) contain the supplementary crystallographic data for this paper. These data can be obtained free of charge from The Cambridge Crystallographic Data Centre via http://www.ccdc.cam.ac.uk/data_request/cif/.

\section{References}

1. Hurd, C. D.; Raterink, H. R. J. Am. Chem. Soc. 1933, 55, 1541.

2. Muller, A. J.; Nishiyama, K.; Griffin, G. W.; Ishikawa, K.; Gibson, D. M. J. Org. Chem. 1982, 47, 2342.

3. Berti, G. Top. Stereochemistry 1973, 7, 93.

4. Zimmerman; H. E.; Abramjian, L. J. Am. Chem. Soc. 1960, 82, 5459.

5. Yadav, V. K.; Balamurugan, R.; Parvez, M.; Yamdagni, R. J. Chem. Soc. Perkin Trans. 1 2001, 323. 